\title{
Aptamer-Based Fluorescent Biosensing of Adenosine Triphosphate and Cytochrome c via Aggregation-Induced Emission Enhancement on Novel Label Free DNA-Capped Silver Nanoclusters/Graphene Oxide Nanohybrids
}

\author{
Mojtaba Shamsipur, ${ }^{*}{ }^{\dagger}$ Karam Molaei, ${ }^{\ddagger}$ Fatemeh Molaabasi, ${ }^{*} ¥$ Saman Hosseinkhani, ${ }^{\S}$ \\ Avat (Arman) Taherpour, ${ }^{\dagger}$ Morteza Sarparast, ${ }^{\$}$ Seyyed Ebrahim Moosavifard,,${ }^{£}$ and Ali \\ Barati $^{\dagger}$
}

† Department of Chemistry, Razi University, Kermanshah 67149-67346, Iran

*Department of Chemistry, Tarbiat Modares University, Tehran 14115-111, Iran

${ }^{¥}$ Department of Biomaterials and Tissue Engineering, Breast Cancer Research Center, Motamed Cancer Institute, ACECR, Tehran 15179-64311, Iran

$\S$ Department of Biochemistry, Tarbiat Modares University, Al Ahmad Street, Tehran, Iran

${ }^{\$}$ Department of Chemistry, Michigan State University, East Lansing MI 48825, USA

${ }^{\mathfrak{f}}$ Department of Advanced Medical Sciences \& Technologies, School of Medicine, Jahrom University of Medical Sciences (JUMS), Jahrom 74148-46199, Iran

*Tel: +98 83 34274515; E-mail: mshamsipur@yahoo.com (M. Shamsipur); and molaabasi.fatemeh@yahoo.com (F. Molaabasi) 


\section{Experimental details}

Apparatus. Fluorescence spectra were carried out on a Perkin-Elmer LS-50B fluorescence spectrometer (Perkin-Elmer, U.K.), equipped with a xenon lamp as excitation source. The bandwidths were set at 15 and $15 \mathrm{~nm}$ for excitation and emission, respectively. A $200 \mu \mathrm{L}$ measurement cell was applied for all the experiments. The absorbance spectra were acquired using with a Model Scinco UV S-2100 (Cinco, Korea). The morphological analysis was obtained by means an EIGMA/VP field emission scanning electron microscopy (FESEM), from Zeiss (Zeiss, Germany) and Philips CM30 transmission electron microscope (Philips, Netherlands) with accelerating voltages of $200 \mathrm{kV}$. X-ray powder diffraction (XRD) measurements were performed using a Philips diffractometer of the X'pert Company with mono chromatized Co $\mathrm{k} \alpha$ radiation (Philips, Netherlands). The fluorescent images were captured using an Olympus BX-51 optical equipped with a CCD camera (Olympus, Japan). Matrix-assisted laser desorption/ionization time-of-flight (MALDI-TOF) mass spectrometry was carried out on a Bruker Daltonics Autoflex II MALDI TOF/TOF system. Circular dichroism (CD) spectra were performed using a J-715 JASCO CD spectrometer (JASCO, Japan) with a cell of $1 \mathrm{~mm}$ path length. The FTIR spectra of samples supported on $\mathrm{KBr}$

pellets were recorded using a Tensor 27 Bruker instrument (Bruker, Japan). All pH measurements were performed at $25 \pm 0.1{ }^{\circ} \mathrm{C}$ by using a Metrohm $713 \mathrm{pH} /$ ion-meter with a standard uncertainty of $0.1 \mathrm{mV}$ (Metrohm, Switzerland).

Cresyl violet and fluorescein in methanol and $0.1 \mathrm{M} \mathrm{NaOH}$ with the already known QYs of 0.54 and 0.79 were chosen as reference for ATP1-AgNCs, Cyt1-AgNCs and (excitation from 540 to $640 \mathrm{~nm}$ ) and ATP2-AgNCs and Cyt2-AgNCs (excitation from 400 to $600 \mathrm{~nm}$ ), respectively. ${ }^{1}$ The relative fluorescence QY of all prepared DNA-stabilized AgNCs were experimentally determined by use of the following equation:

$Q_{X}=Q_{r} *\left(\frac{I_{x}}{I_{r}}\right) *\left(\frac{A_{r}}{A_{x}}\right) *\left(\frac{\eta_{x}^{2}}{\eta^{2}{ }_{r}}\right)$ 
where $r$ and $x$ refer to the standard reference and the sample of interest respectively, Q is the QY, $I$ is the integrated emission spectra, $\eta$ is the refractive index of the solvent and, and $A$ is the absorbance. A was kept below 0.1. The QYs of AgNCs were consistent with the relative fluorescent intensity of the AgNCs.

Table S1. The quantum yields (QY) of as prepared DNA-stabilized AgNCs

\begin{tabular}{llll} 
Nanocluster & Standard & $\boldsymbol{\lambda}_{\text {excitation }}$ & QY (\%) \\
Type & Reference & $(\mathbf{n m})$ & \\
ATP1-AgNCs & Cresyl Violet & 550 & $4.19 \pm 1$ \\
ATP2-AgNCs & Cresyl Violet & 550 & $9.85 \pm 1$ \\
Cyt1-AgNCs & Cresyl Violet & 560 & $4.35 \pm 1$ \\
Cyt2-AgNCs & Fluorescein & 470 & $4.27 \pm 1$ \\
\hline
\end{tabular}

Synthesis of graphene oxide (GO) using modified Hummers- method. GO was prepared according to the Hummer's method by the exfoliation of natural graphite with some modification. $^{2}$ Briefly, $3.0 \mathrm{~g}$ of natural graphite powder and $20.0 \mathrm{~g}$ of potassium permanganate were dispersed with the acid $(400 \mathrm{~mL})\left(\mathrm{HNO}_{3}: \mathrm{H}_{2} \mathrm{SO}_{4}=1: 9\right)$ and stirred for 12 h at $60{ }^{\circ} \mathrm{C}$. Thereafter, $10 \mathrm{~mL}$ of $30 \% \mathrm{H}_{2} \mathrm{O}_{2}$ was slowly added in the obtained mixed liquor and stirred then for 60 minutes resulting in bright yellow colored end product. Then, the mixture was filtered by a nylon film and washed with double distilled water twice $(200 \mathrm{~mL})$. Ultimately, the solid was washed abundantly with double distilled water until a neutral $\mathrm{pH}$ was reached, dried under vacuum at $60^{\circ} \mathrm{C}$ and stored in refrigerator for further use.

MS measurement of ATP1-AgNCs; Matrix-assisted laser desorption/ionization-time of-flight (MALDI-TOF) mass spectrometry was used to find the number of the Ag atoms in ATP1AgNCs. MALDI-TOF mass spectra ATP1-AgNCs and ATP1 were collected in linear mode 
using the matrix 2,5-dihydroxybenzoic acid. The mass spectra of ATP1 and as-prepared ATP1-AgNCs are illustrated in Fig. S8. ATP1 shows a broad mass peak around m/z 12088 Da but mass peaks corresponding to ATP1-AgNCs are shifted toward right, appearing at 12592 and $13785 \mathrm{Da}$. These difference can be attributed to 5 and 15 atoms of silver.

CD studies of DNA-AgNCs and their nanohybrids with GO. CD wavelength spectra between 200 and $300 \mathrm{~nm}$, at $25^{\circ} \mathrm{C}$, were obtained with $200 \mu \mathrm{L}$ of sample in a quartz cell of $1.0 \mathrm{~cm}$ path length. Each wavelength spectrum was the result of averaging two consecutive scans with a bandwidth of $1.0 \mathrm{~nm}$ and a time constant of 12 seconds. Wavelength spectra were processed by first subtracting a blank spectrum followed by automated line smoothing. In summary, Aliquots $(198.0 \mu \mathrm{L})$ of Phosphate solutions (10 mM, pH 7.4) and $2.0 \mu \mathrm{L}$ of the as-prepared ATP1-AgNCs were first mixed and subjected to CD measurement as described above. $5.0 \mu \mathrm{L}$ of aqueous dispersion of GO $\left(246 \mu \mathrm{g} \mathrm{mL}^{-1}\right)$ was added into above mixture and subjected after 10 min to $\mathrm{CD}$ measurement. Finally, in order to investigate the changes in the DNA conformation of ATP1-AgNCs/GO nanohybrid, phosphate solution containing ATP $\left(1 \times 10^{-6} \mathrm{M}\right)$ was added into above mixture and after 5 min subjected to $\mathrm{CD}$ measurement.

Cell Culture. The mES cells were purchased from American type culture collection (ATCC) (Manassas, VA, USA). The mES cells were cultured under feeder-free condition. The cells were cultured on flasks coated with $0.1 \%$ gelatin in ES maintenance (R2i condition) medium which consisted of DMEM/F12 (Gibco, 980891), 2 mM L-glutamine (Gibco, 25030081), 1\% nonessential amino acids (Gibco, 11140-035), penicillin/streptomycin (Gibco, 15070-063), $0.1 \mathrm{mM} \beta$-mercaptoethanol (Sigma-Aldrich, M7522), $1000 \mathrm{U} \mathrm{mL}^{-1}$ mouse leukemia inhibitory factor (LIF, Royan Institute) and Small molecules PD0325901 (1 $\mu \mathrm{M}$, Sigma-Aldrich) and SB431542 (10 $\mu \mathrm{M}$, Sigma-Aldrich) for maintenance of pluripotency. To induce apoptosis, doxorubicin (Ebendoxo, EBEWE Pharma Ges) at a concentration of 0.5 
$\mu \mathrm{M}$ was added to the mESCs and incubated at $37^{\circ} \mathrm{C}$. To prepare cytosolic fractionation, cells were lysed in hypotonic buffer (10 mM HEPES-KOH pH 7.5, $1.5 \mathrm{mM} \mathrm{MgCl} 2,10 \mathrm{mM} \mathrm{KCl}$, 1.0 mM Na-EDTA, $250 \mathrm{mM}$ sucrose and 1.0 mM PMSF) 2, 6, 12 and $24 \mathrm{~h}$ after apoptosis induction. Following centrifugation at $15,000 \times \mathrm{g}$ for $30 \mathrm{~min}$ at $4{ }^{\circ} \mathrm{C}$, cytosolic extract (supernatants) were collected and the protein concentration were determined using Bradford method. The concentration of protein after $2,6,12$ and $24 \mathrm{~h}$ was $0.92,0.57,0.8,1.12$ and 1 $\mu \mathrm{g} \mu \mathrm{L}^{-1}$, respectively. The untreated cells were used as a control.

Bacterial cell culture- LB medium was inoculated with a fresh bacterial colony (of E. coli DH5 $\alpha$ ) and incubated at $37{ }^{\circ} \mathrm{C}$ overnight. The cells were then harvested by centrifugation at $5000 \mathrm{~g}$ for $15 \mathrm{~min}$. The cells pellet was resuspended in lysis buffer $(50 \mathrm{mM}$ $\mathrm{NaH}_{2} \mathrm{PO}_{4}, 300 \mathrm{mM} \mathrm{NaCl}, 10 \mathrm{mM}$ imidazol, $\mathrm{pH}=8$ ) and was stored at $-70{ }^{\circ} \mathrm{C}$ for the next step. The ATP content in the cell lysate was evaluated using our designed aptasenseor. The result compared with those acquired by conducting a luciferin- luciferase luminescent assay. ${ }^{3}$ In luciferin-luciferase assay data were obtained as relative light units (RLU) and converted to ATP (nM) by means of a calibration curve conducted with a known ATP standard.

Theoretical calculations. The main structures of the $\operatorname{Ag}_{n}$-nanoclusters ( $\mathrm{n}=5$ and 15$)$, GO, the convex (I) and concave (II) complexes of $\mathrm{GO}^{-\mathrm{Ag}_{\mathrm{n}}}$ have performed by QM calculations. The calculations on the structures of the $\operatorname{Ag}_{n}$-nanoclusters ( $n=5$ and 15) and the complexes with the designed graphene oxide profile have undertaken by UHF/6-31G* method. The results of the selected structural data for the $\mathrm{NCs}$ of $\operatorname{Ag}_{n}(\mathrm{n}=5$ and 15), i.e. bond lengths (in $\AA$ ), bond angles (in ${ }^{\circ}$ ) and the structures were determined and displayed in the Fig. S14 (I and II). A series of different clusters formed by addition of closed shells structures. Each of the presented clusters of $\operatorname{Ag}_{n}(n=5$ and 15) represents the core of the subsequent clusters. In 2015, Debnath et al. have reported a density functional theory (DFT) and partial density of states (PODS) studies on nanocluster of $\mathrm{Ag}_{13}$ for its potential in optoelectronics 
and catalysis properties. ${ }^{4}$ In their studies, they have reported the decahedral arrangement for $\mathrm{Ag}$ atoms in the nanocluster of $\mathrm{Ag}_{13}$. One of the $\mathrm{Ag}$ atoms locates at the core of the structure and $12 \mathrm{Ag}$ arranged around the core $\mathrm{Ag}$ atom as the decahedral cluster. In Fig. S14 have demonstrated the calculated decahedral NCs of $\operatorname{Ag}_{n}(\mathrm{n}=5$ and 15), (A) Ag-Ag bond lengths, B) bond angles and C) the space filling of the $\operatorname{Ag}_{n}$ ( $n=5$ and 15) clusters). The biggest and

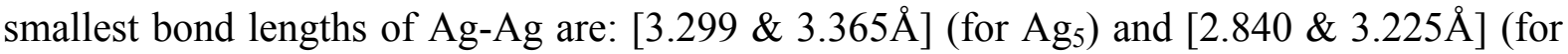
$\left.\mathrm{Ag}_{15}\right)$ on the rectangular part of the decahedral side of the cluster. The average of the Ag-Ag bond lengths is 3.33 and $3.12 \AA$ for $\mathrm{Ag}_{5}$ and $\mathrm{Ag}_{15}$, respectively. The point group of the $\mathrm{NCs}$ structures of $\mathrm{Ag}_{5}$ and $\mathrm{Ag}_{15}$ are: $\mathrm{D}_{3 h}$ and $\mathrm{C}_{2 h}$, respectively.

The pathways of the electron transfer (ET) between the energy levels and molecular orbitals of the metal $\mathrm{NCs} \mathrm{Ag}_{5}$ and $\mathrm{Ag}_{15}$ are very important to interpret the fluorescent properties of the complexes with the GO structures. In Fig. S16 has shown the molecular orbitals of the $\mathrm{Ag}_{5}$ and $\mathrm{Ag}_{15} \mathrm{NCs}$ and the related energy levels. The calculated energy gaps of aHOMO-aLUMO of $\mathrm{Ag}_{5}$ and $\mathrm{Ag}_{15}$ have determined equal to: 3.78 and $4.45 \mathrm{eV}$ and their calculated energy gaps of bHOMO-bLUMO are: 4.16 , and $3.22 \mathrm{eV}$, respectively. The bad gap of aLUMO and bLUMO energy levels of $\mathrm{Ag}_{5}$ and $\mathrm{Ag}_{15} \mathrm{NCs}$ are: 0.30 and $0.99 \mathrm{eV}$, respectively. The bad gap energy levels of aHOMO and bHOMO of $\mathrm{Ag}_{5}$ and $\mathrm{Ag}_{15} \mathrm{NCs}$ are: 0.04 and $0.24 \mathrm{eV}$ respectively. In $\mathrm{Ag}_{5} \mathrm{NCs}$ the electron transfer between aHOMO-aLUMO is simpler than bHOMO-bLUMO, but in the $\mathrm{Ag}_{15}$ NCs the electron transfer between bHOMObLUMO is simpler than aHOMO-aLUMO, so, the relaxation time of electrons in "b" pathway is smaller and relaxation rate is faster than "a" pathways. In Fig. S17 (I and II) were demonstrated the three electron transfer pathways in the $\mathrm{Ag}_{5}$ and $\mathrm{Ag}_{15} \mathrm{NCs}$ structures. In the $\mathrm{Ag}_{5}$ the pathway (A) shows the emissions E1 and E2 by electron transfer process $\mathrm{bHOMO} \rightarrow \mathrm{bLUMO} \rightarrow \mathrm{aLUMO} \rightarrow \mathrm{bHOMO}$. The pathway (B) and (C) show the other emissions E3 and E4 by electron transfer process $\mathrm{bHOMO} \rightarrow \mathrm{aLUMO} \rightarrow \mathrm{bLUMO} \rightarrow \mathrm{bHOMO}$ 
and $\mathrm{aHOMO} \rightarrow \mathrm{aLUMO} \rightarrow \mathrm{bLUMO} \rightarrow \mathrm{aHOMO}$, respectively, see Fig. S17 (I). In $\mathrm{Ag}_{15}$ the pathway (A) shows the emissions E1 and E2 by electron transfer processes $\mathrm{aHOMO} \rightarrow \mathrm{aLUMO} \rightarrow \mathrm{bLUMO} \rightarrow \mathrm{aHOMO}$. The pathways (B) and (C) show the other emissions E3 and E4 by electron transfer process aHOMO $\rightarrow \mathrm{bLUMO} \rightarrow \mathrm{aLUMO} \rightarrow \mathrm{aHOMO}$ and $\mathrm{bHOMO} \rightarrow \mathrm{bLUMO} \rightarrow \mathrm{aLUMO} \rightarrow \mathrm{bHOMO}$, respectively, see Fig. S17 (II). It seems that for ET-process the pathway (A) is better than (B) and (C) if the enough energy irradiates to the $\mathrm{Ag}_{5}$ and $\mathrm{Ag}_{15} \mathrm{NCs}$ structures.

It was investigated that GO has recognized as a universal electron acceptor due to the exceptional electronic and optical properties. In 2014, Wen et al. reported an unusual ultrafast electron transfer occurring in the nano composites of Au NCs with GO in which GO acts as


the Tube model (A), the convex and concave curved surfaces with the functional groups (B) and space filling model of the GO profile (C). The convex and concave surfaces of the designed GO profile are the place for locating the $\mathrm{Ag}_{\mathrm{n}} \mathrm{NCs}$ in this modeling (Fig. S19). The distances between the $\mathrm{Ag}_{\mathrm{n}} \mathrm{NCs}$ and the convex and concave surfaces of the designed GO

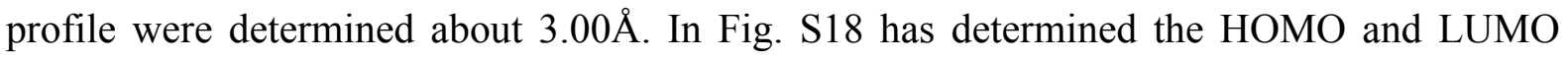
molecular orbitals of the GO profile. In notice to the close HOMO (-1) to HOMO and LUMO $(+1)$ to LUMO energy levels it is possible that HOMO $(-1)$ and LUMO $(+1)$ to take part in the ET-process in GO and it has made a proper space for ET-process. 


\section{Results}


Figure S1. Absorption and emission spectra of DNA-stabilized AgNCs. Inset: AgNCs under UV irradiation (365 nm). 

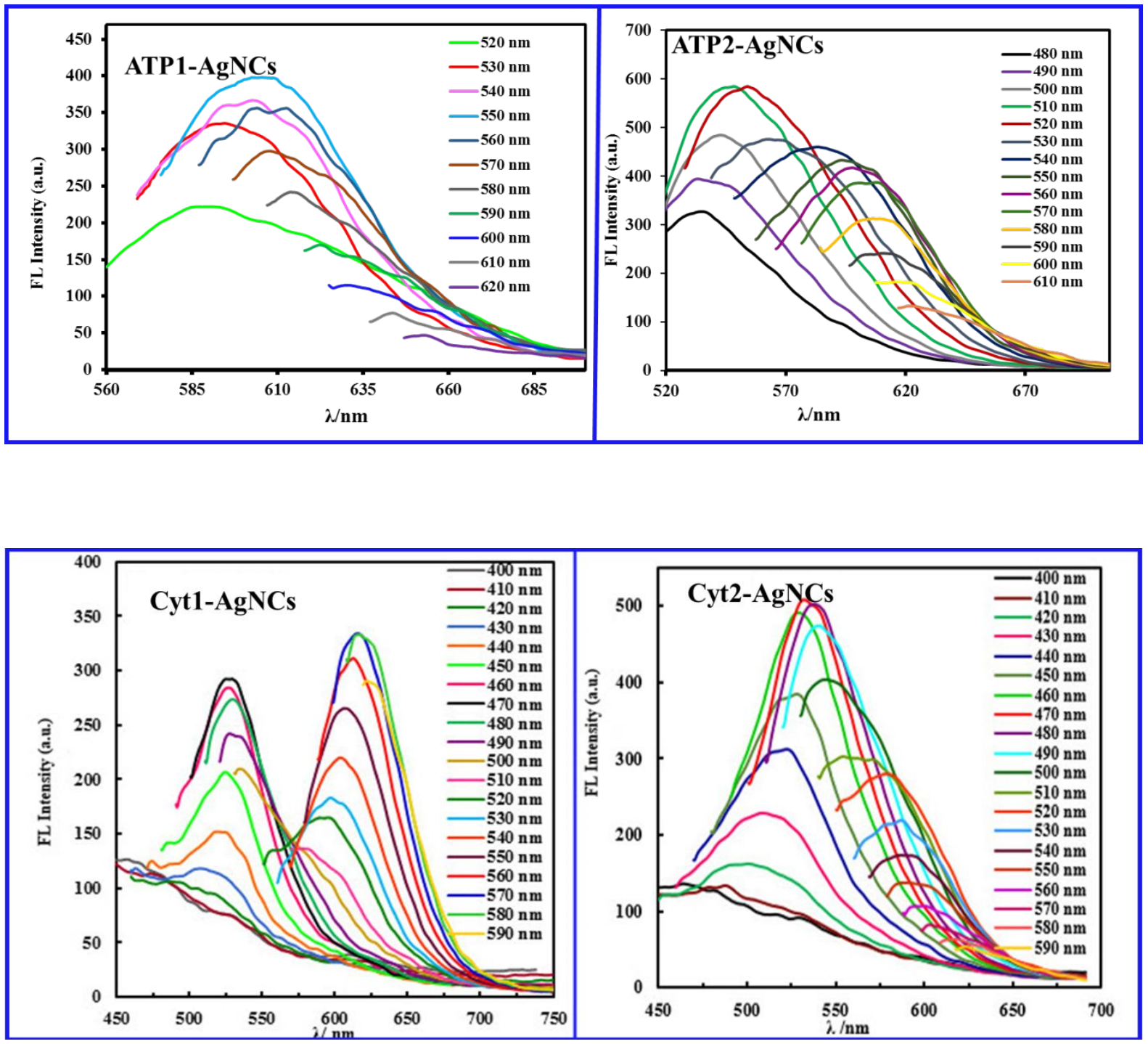

Figure S2. Emission spectra of DNA-stabilized AgNCs at different excitation wavelengths (on the left) with a $10 \mathrm{~nm}$ increment. 

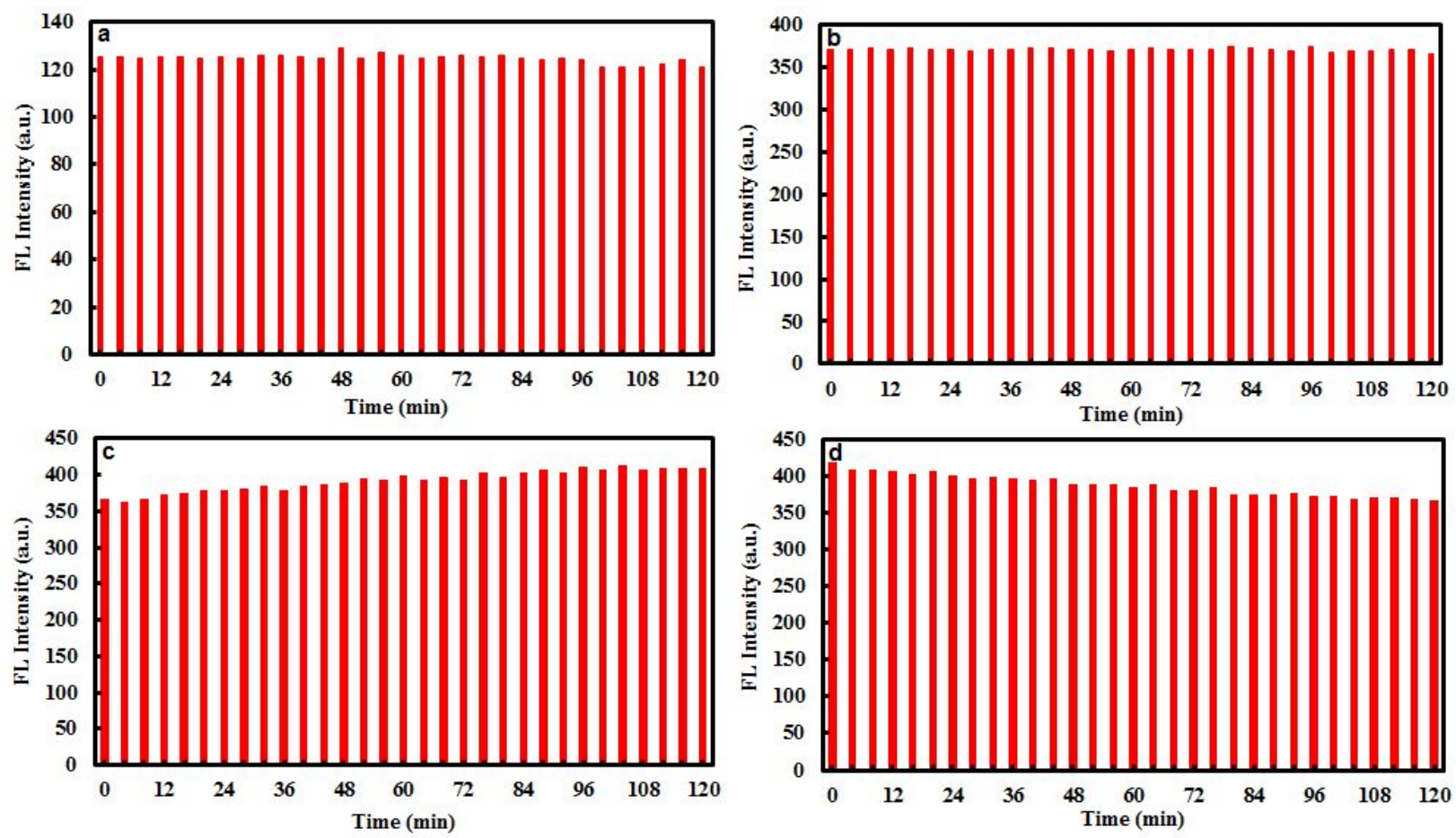

Figure S3. Photostability of (a) ATP1-AgNCs, (b) ATP2-AgNCs, (c) Cyt1-AgNCs and (d) Cyt2-AgNCs.
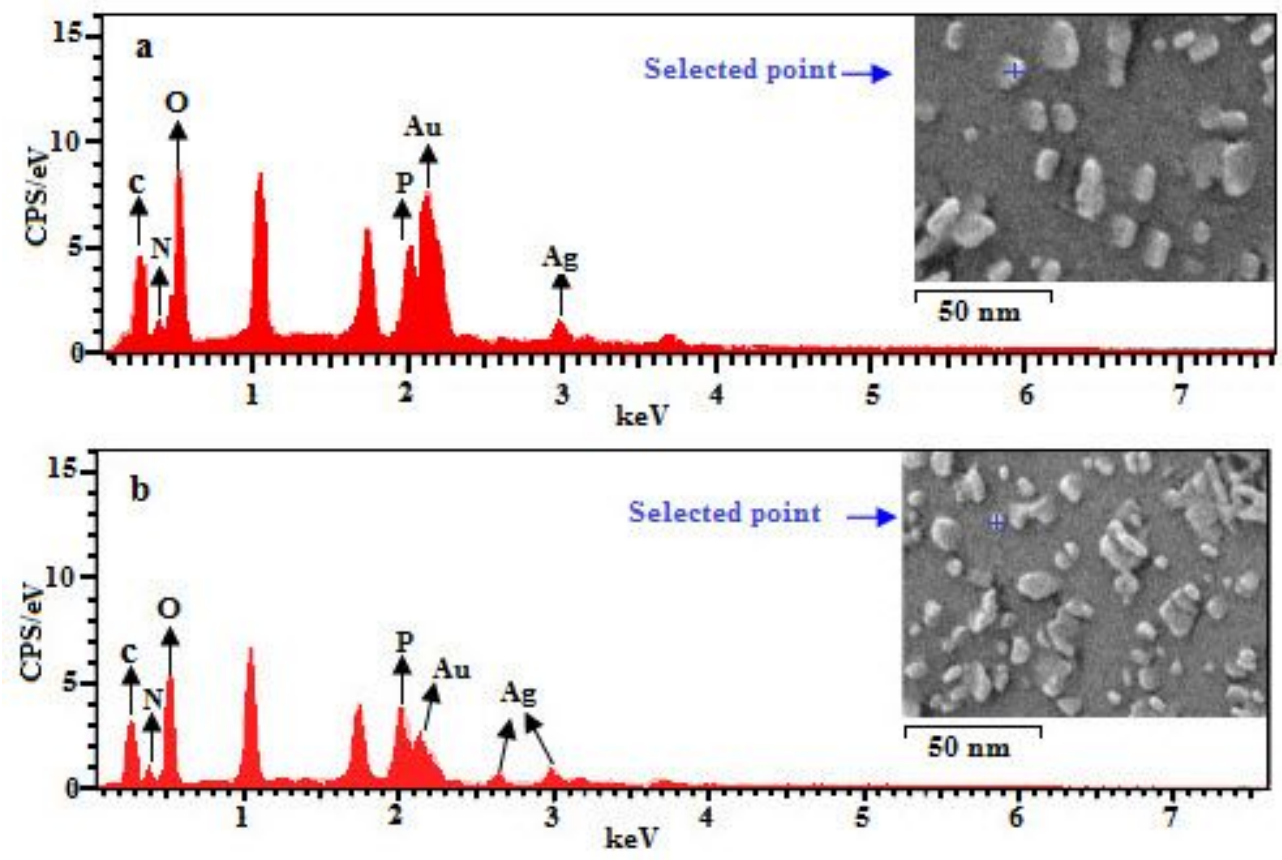

Figure S4. EDX spectra of ATP1-AgNCs (a) and Cyt1-AgNCs (b) (Inset: FE-SEM images ATP1-AgNCs (a) and Cyt1-AgNCs (b)). 


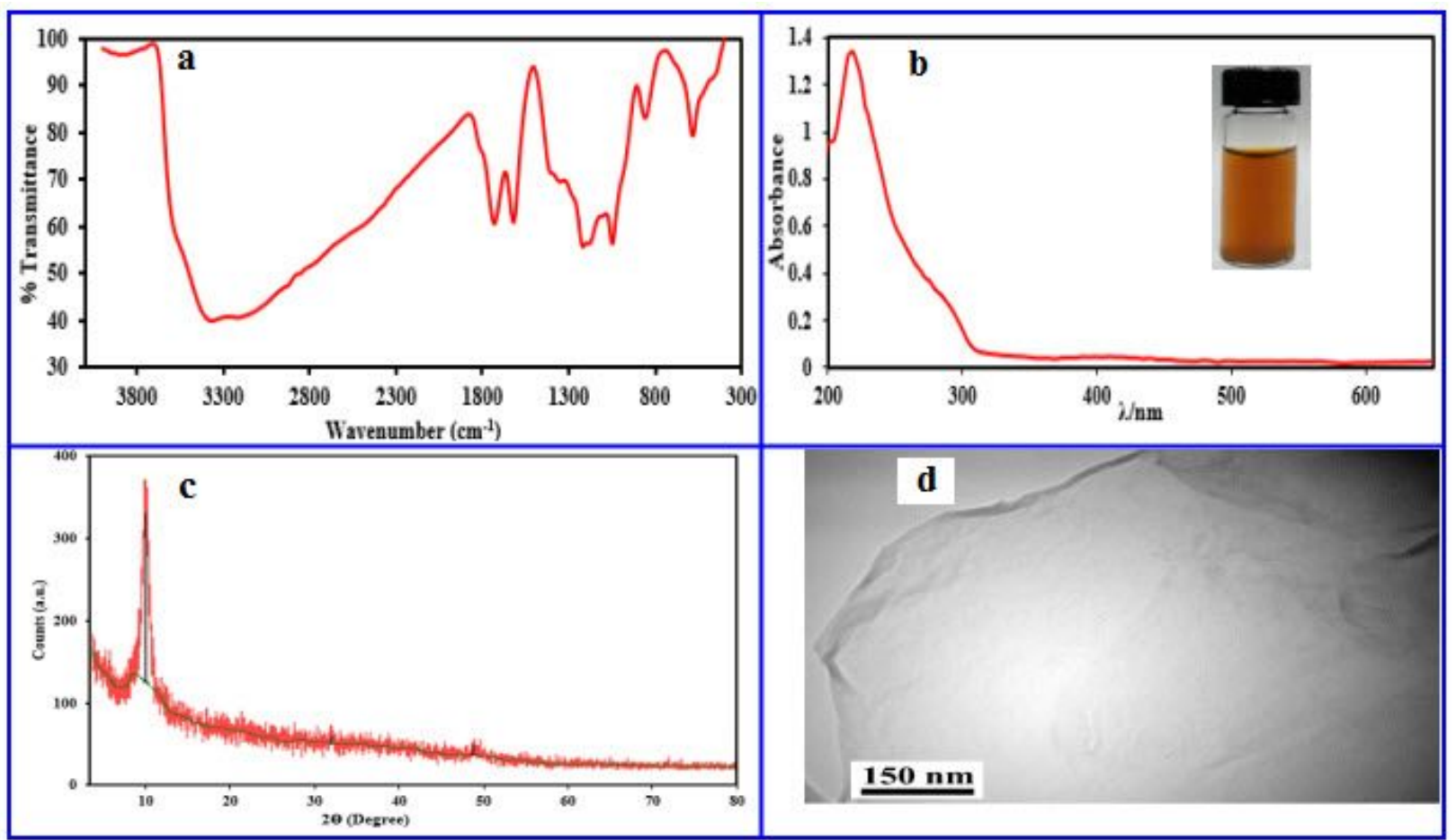

Figure S5. FTIR spectra of GO (a), UV-vis spectra of GO aqueous dispersions (b), XRD patterns (c), and TEM image of the GO (d). Inset present photograph of a microvial containing dispersions $\left(246 \mu \mathrm{g} \mathrm{mL}^{-1}\right)$ of $\mathrm{GO}$ in water.

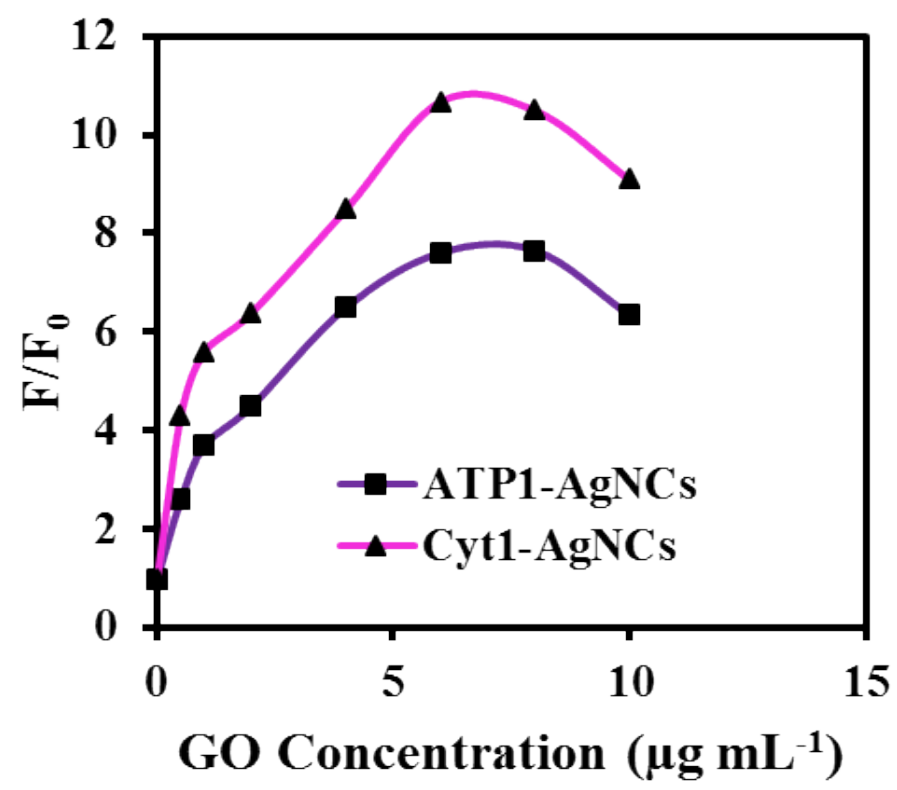

Figure S6. The influence of the different concentration of GO on signal enhancing ATP1$\operatorname{AgNCs}(\mathrm{a})$ and Cyt1-AgNCs (b) was investigated over the range of 0-10 $\mu \mathrm{g} \mathrm{mL}^{-1}$. 

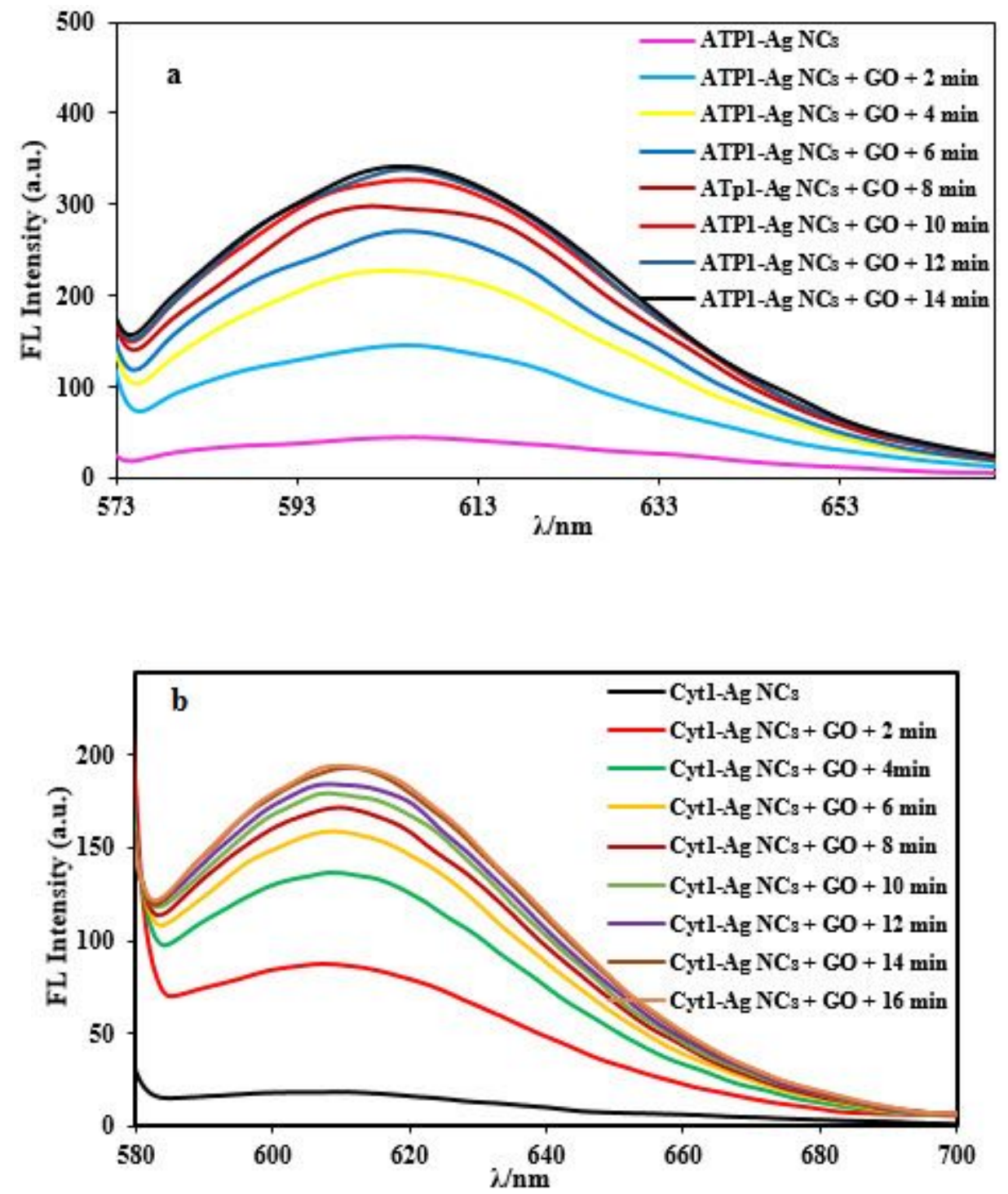

Figure S7. Fluorescence enhancing of ATP1-Ag NCs (a) and Cyt1-Ag NCs (b) in phosphate buffer by GO as a function of time. Excitations were 550 and $560 \mathrm{~nm}$ for ATP1-Ag NCs and Cyt1-Ag NCs, respectively. 


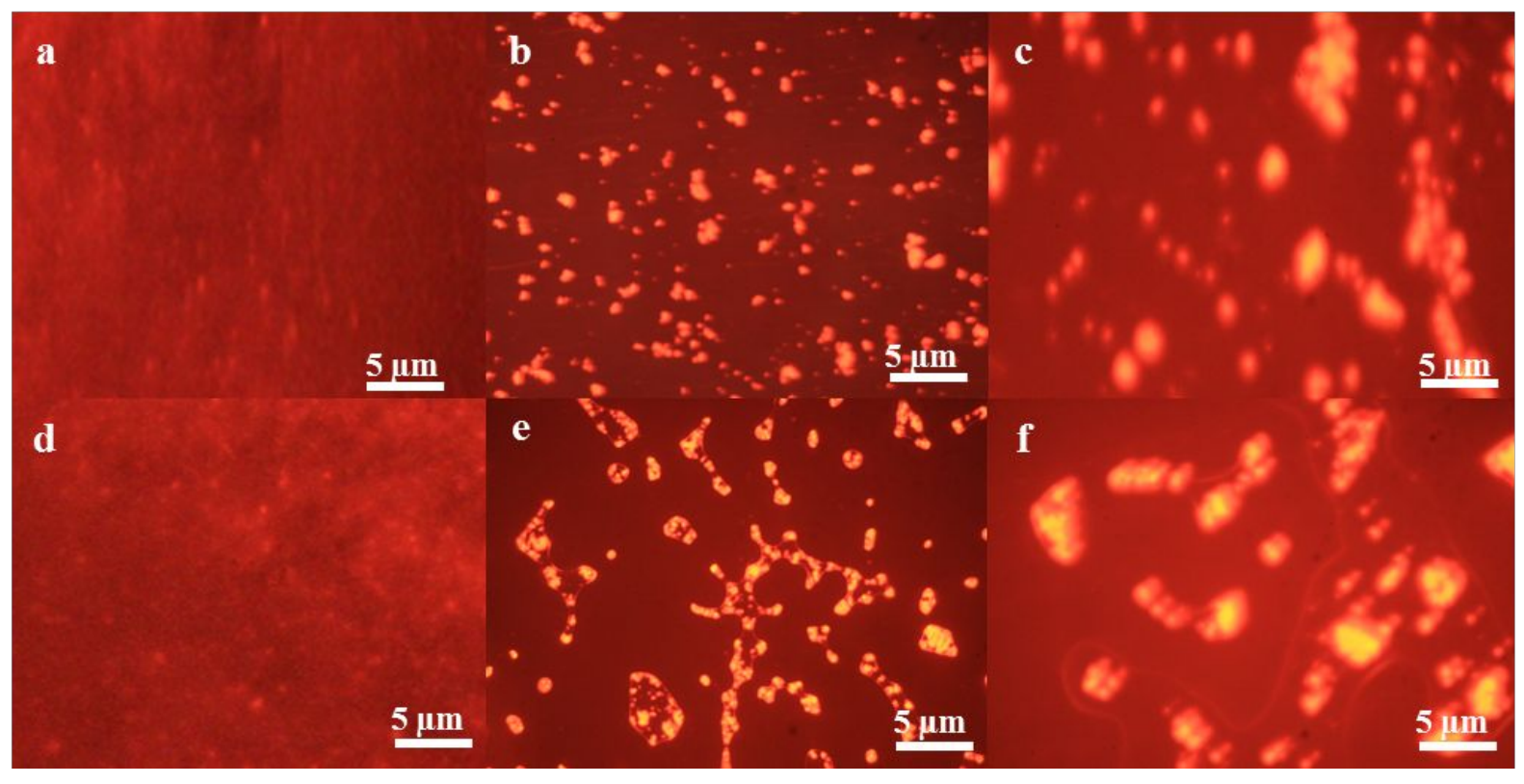

Figure S8. (Top) fluorescence microscopy image of ATP1-AgNCs at 0 min (a), 5 min (b) and 15 min (c) after GO contact; (Bottom) fluorescence microscopy image of Cyt1-AgNCs at $0 \mathrm{~min}(\mathrm{~d}), 5 \mathrm{~min}(\mathrm{e})$ and $15 \mathrm{~min}(\mathrm{f})$ after GO contact. 



Figure S9. Fluorescence spectra of the ATP1-AgNCs and Cyt1-AgNCs in $20 \mathrm{mM}$ phosphate buffer in the absence and presence $10 \mu \mathrm{M}$ of cysteine and $1 \mathrm{M}$ of $\mathrm{NaCl}$.


Figure S10. Fluorescence spectra of the ATP1-AgNCs and Cyt1-AgNCs in $20 \mathrm{mM}$ phosphate buffer solution in the presence of different $\mathrm{H}_{2} \mathrm{O}_{2}$ concentration. 

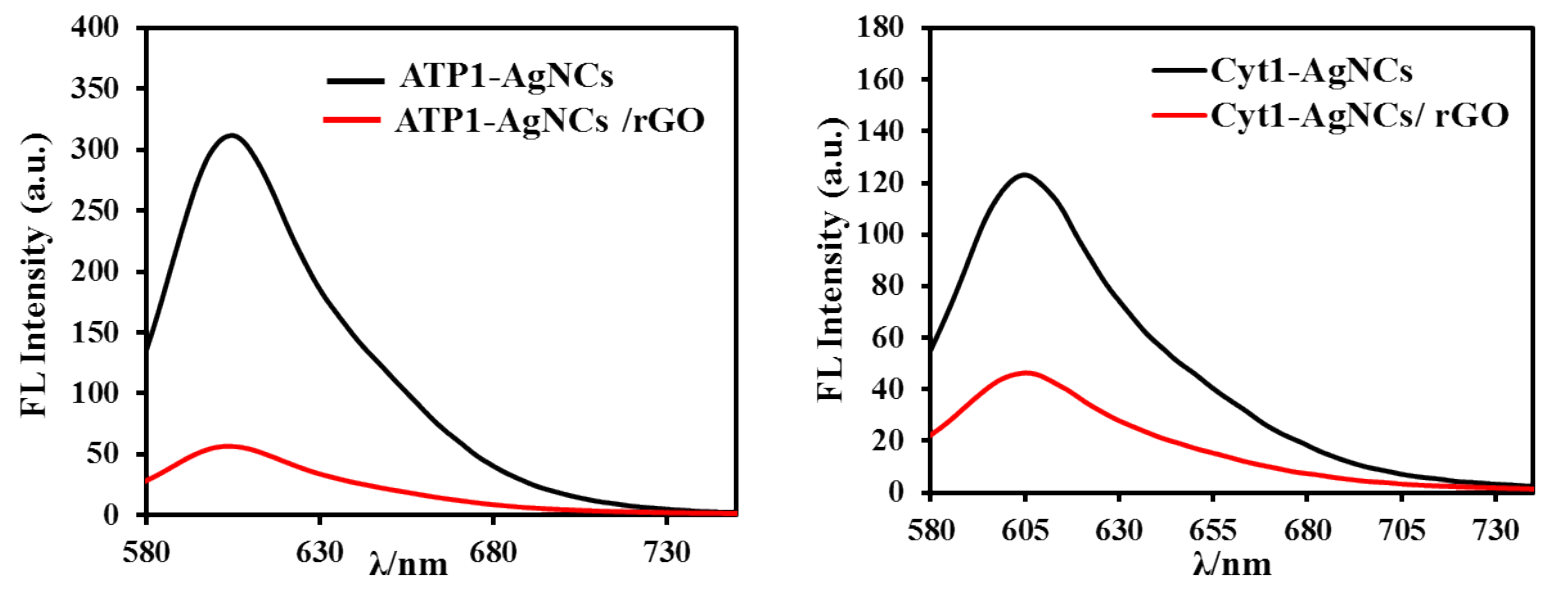

Figure S11. Fluorescence spectra of ATP1-AgNCs and Cyt1-AgNCs in $20 \mathrm{mM}$ phosphate buffer in the absence and the presence of reduced graphene oxide (rGO).
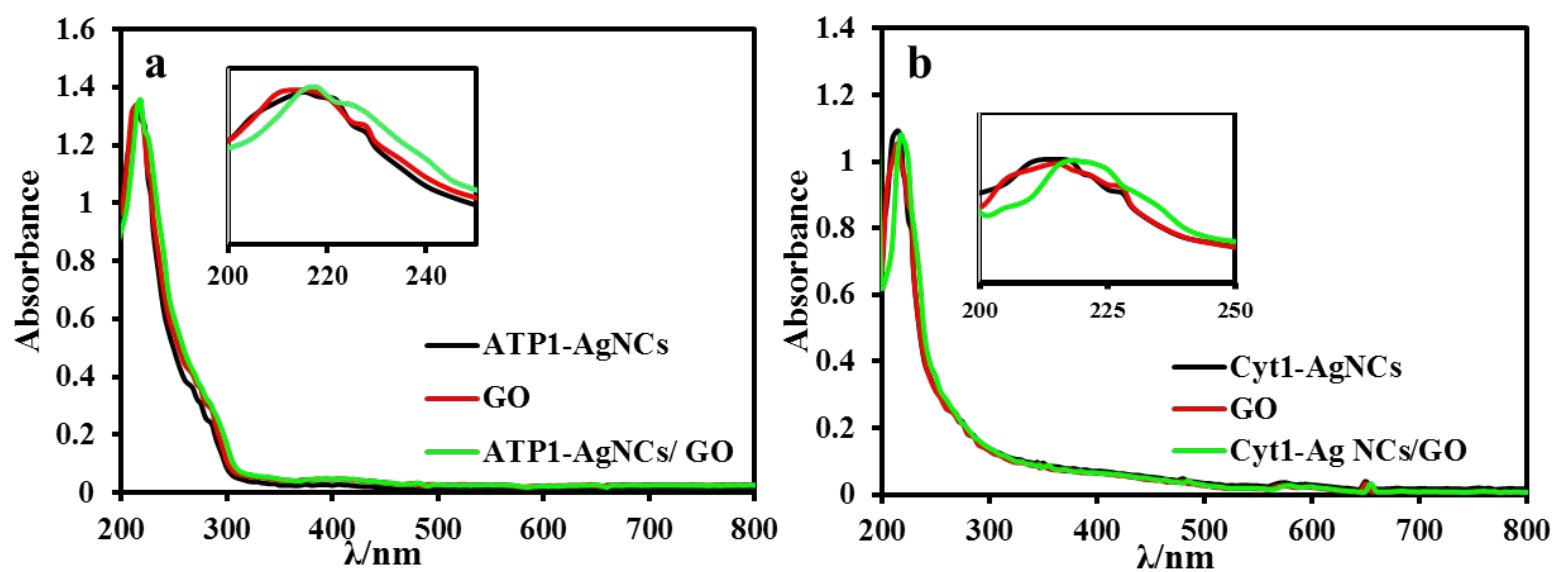

Figure S12 UV-vis absorption spectra of (a) ATP1-Ag NCs, GO and ATP1-Ag NCs /GO system, (b) Cyt1-Ag NCs, GO and Cyt1-Ag NCs/GO system. 


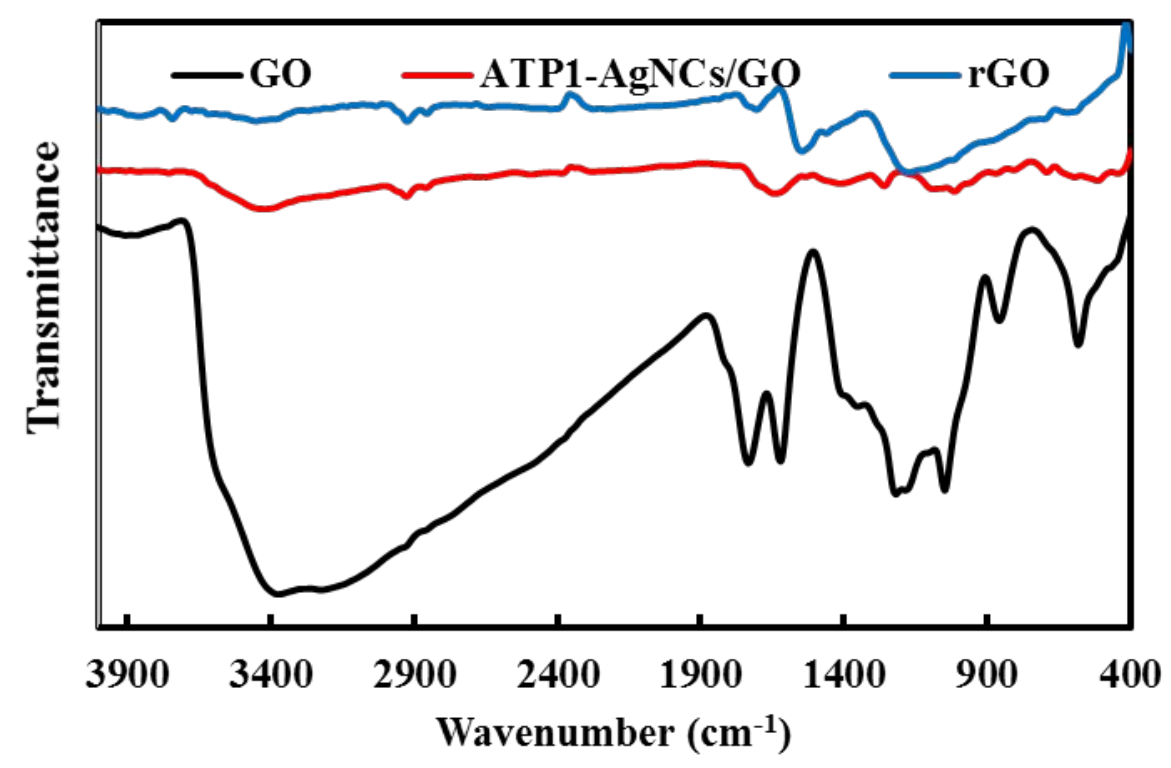

Figure S13. FT-IR spectra of GO, ATP1-AgNCs/rGO and rGO.


Figure S14 The curved structure of the graphene oxide profile (18.84 $\mathrm{A}$ x $18.15 \AA$ ). (A) Tube model, (B) Convex and concave curved surfaces with the functional groups, (C) Space filling model of the graphene oxide profile. 
(A)

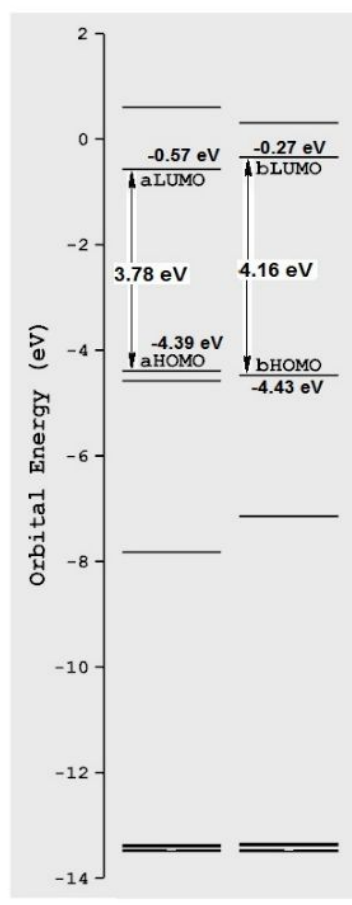

(B)



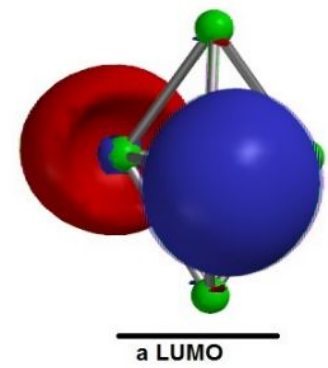
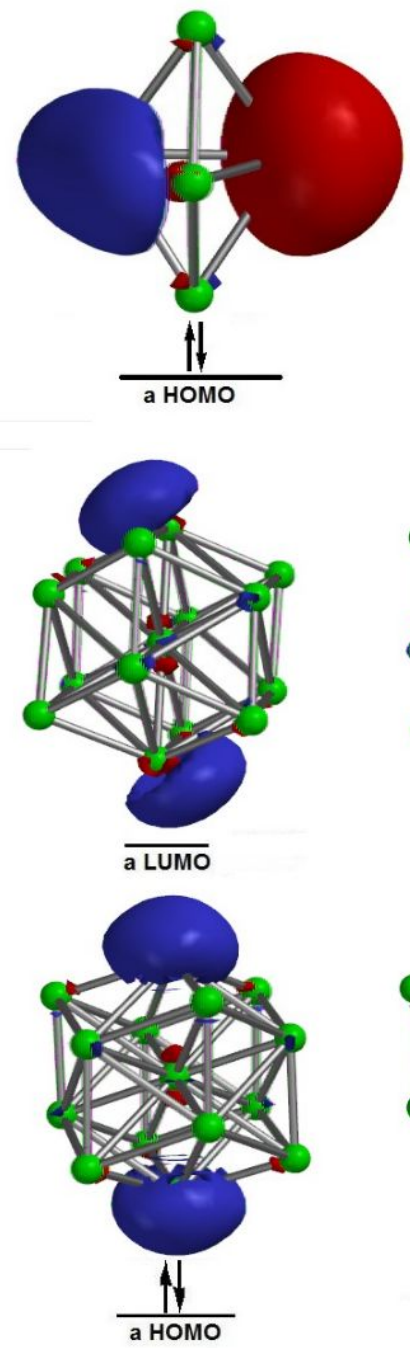
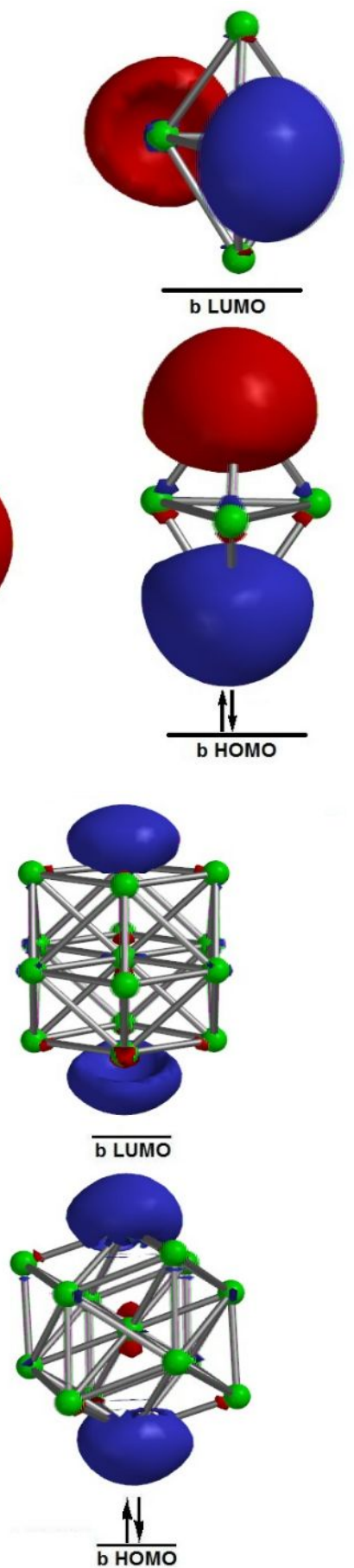

Figure S15 Molecular orbitals of the $\operatorname{Ag}_{n}(n=5$ and 15) clusters (A and $B)$ and their calculated energy gaps aHOMO-aLUMO and bHOMO-bLUMO. 


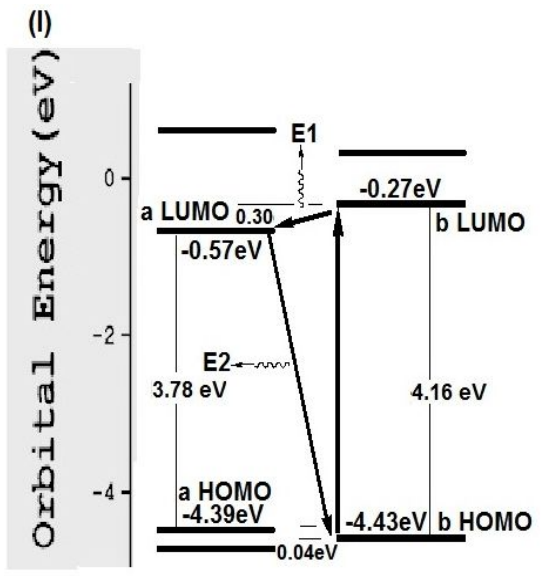

(A)

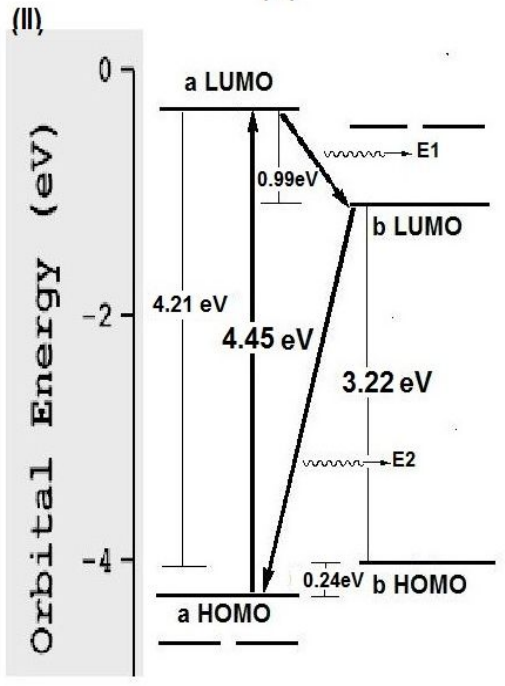

(A)

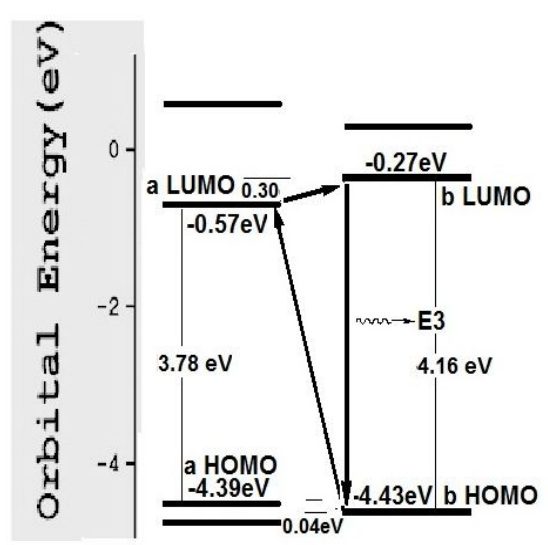

(B)

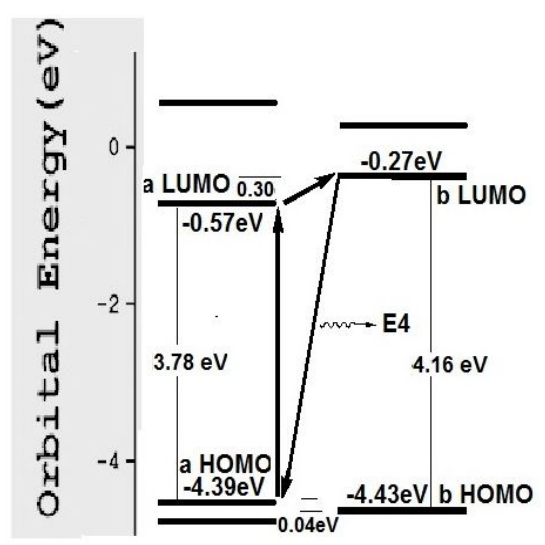

(C)

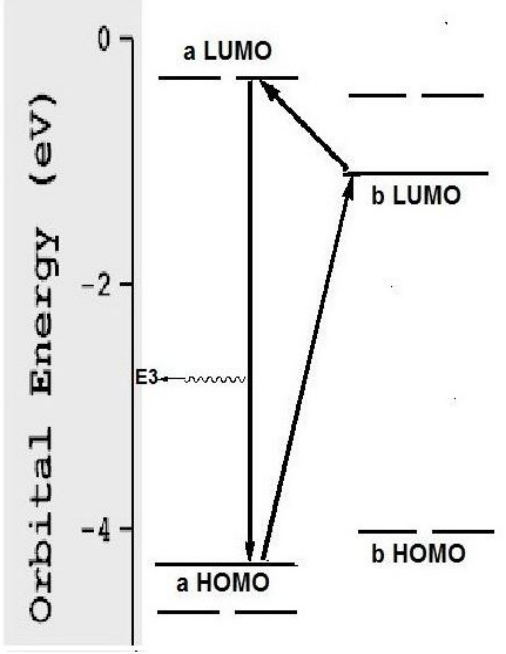

(B)



(C)

Figure S16. The three electron transfer pathways in the $\operatorname{Ag}_{\mathrm{n}}(\mathrm{n}=5$ and 15$)$ nanocluster structures. (I) $\mathrm{Ag}_{5}$ : The pathway (A) shows the emissions E1 and E2 by electron transfer process $b H O M O \rightarrow b L U M O \rightarrow a L U M O \rightarrow b H O M O$. The pathway $(\mathrm{B})$ and $(\mathrm{C})$ show the other emissions E3 and E4 by electron transfer process $\mathrm{bHOMO} \rightarrow \mathrm{aLUMO} \rightarrow \mathrm{bLUMO} \rightarrow \mathrm{bHOMO}$ and $\mathrm{aHOMO} \rightarrow \mathrm{aLUMO} \rightarrow \mathrm{bLUMO} \rightarrow \mathrm{aHOMO}$, respectively. (II) $\mathrm{Ag}_{15}$ : The pathway (A) shows the emissions $\mathrm{E} 1$ and $\mathrm{E} 2$ by electron transfer process $\mathrm{aHOMO} \rightarrow \mathrm{aLUMO} \rightarrow \mathrm{bLUMO} \rightarrow \mathrm{aHOMO}$. The pathways $(\mathrm{B})$ and $(\mathrm{C})$ show the other emissions E3 and E4 by electron transfer process aHOMO $\rightarrow$ bLUMO $\rightarrow a L U M O \rightarrow a H O M O$ and $\mathrm{bHOMO} \rightarrow \mathrm{bLUMO} \rightarrow \mathrm{aLUMO} \rightarrow \mathrm{bHOMO}$, respectively. 




Figure S17. HOMO and LUMO molecular orbitals of the graphene oxide profiles. 


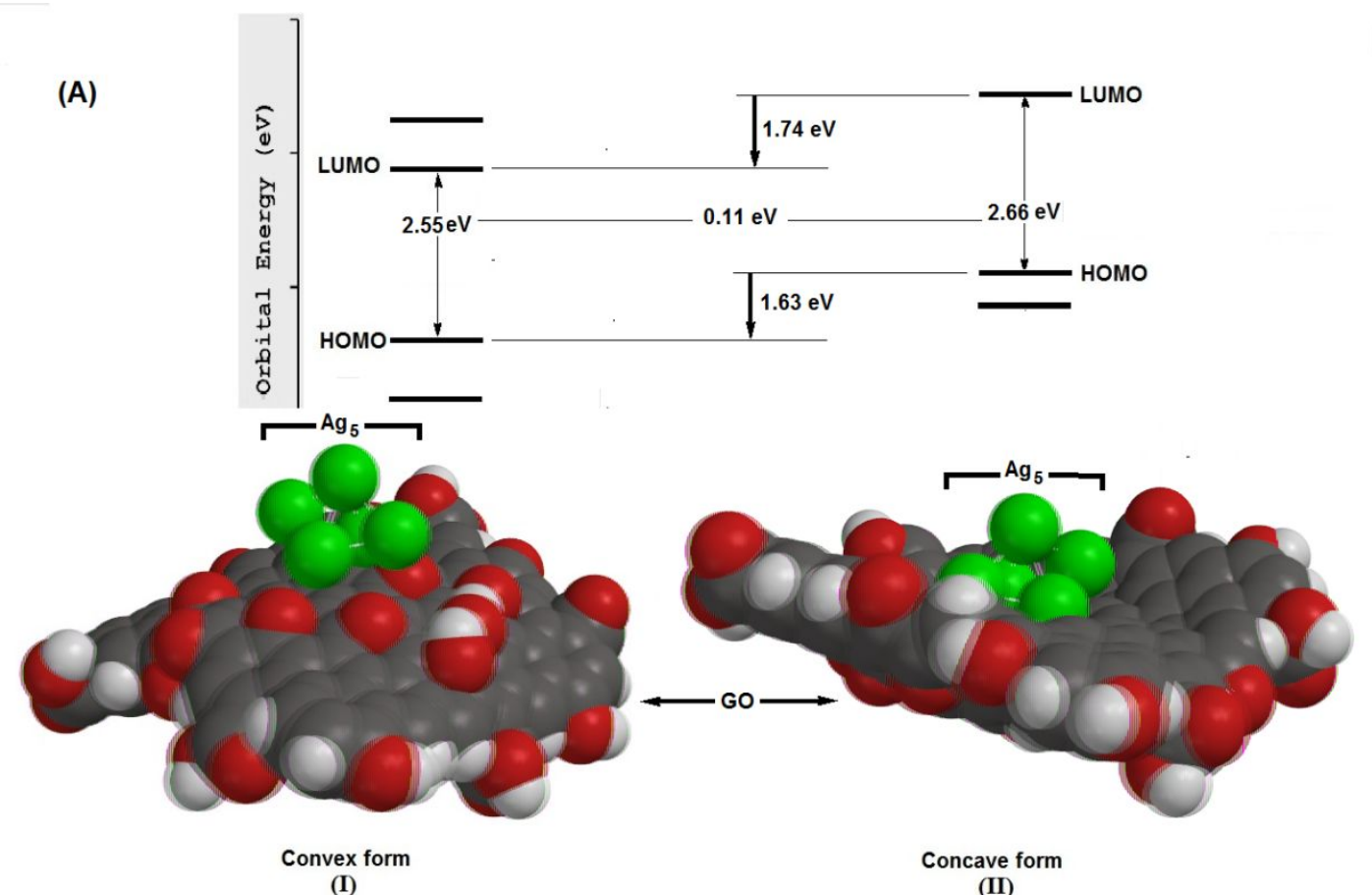

(B)
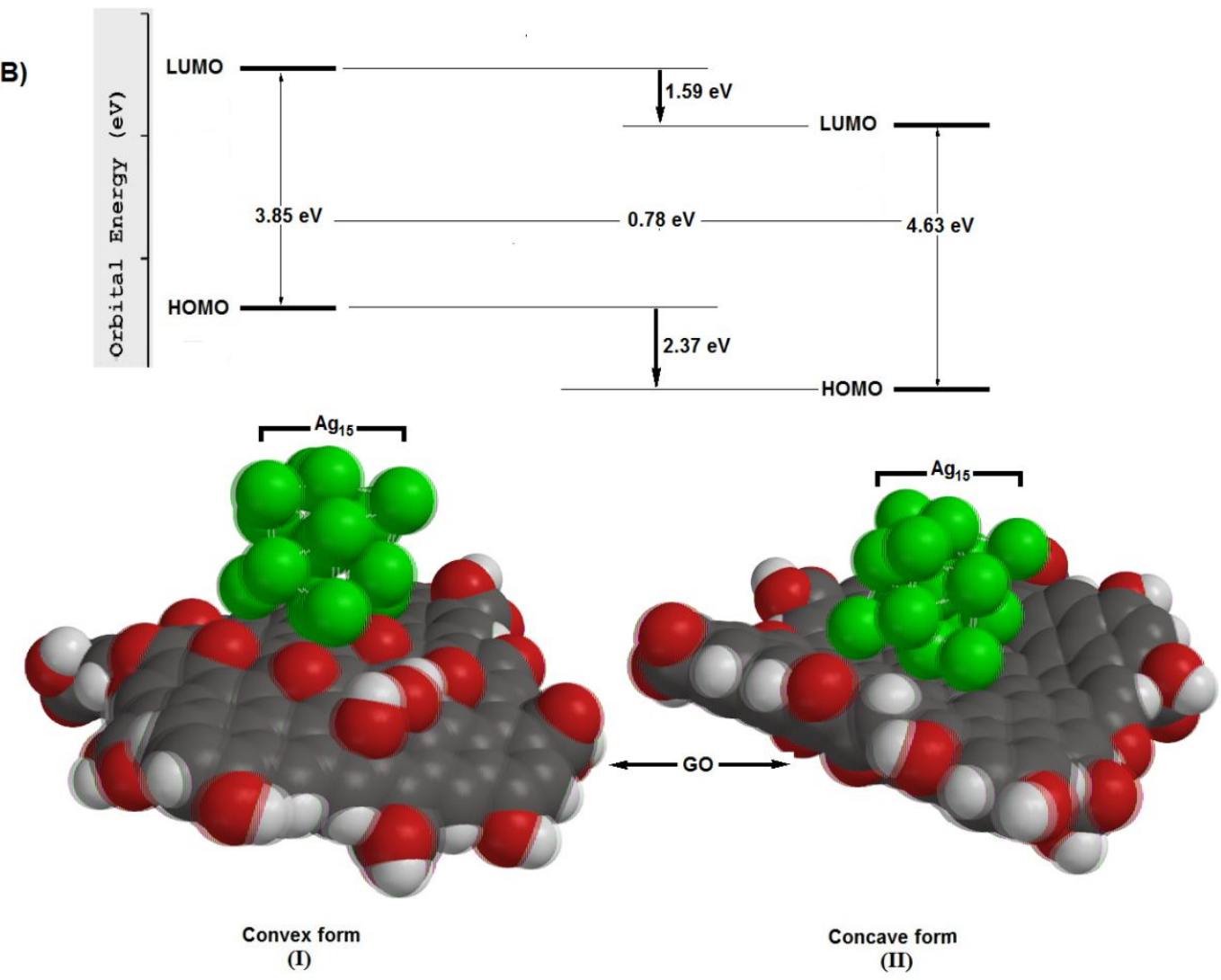

Figure S18. The calculated HOMO and LUMO molecular orbitals of the graphene oxide (GO) profile with the $\operatorname{Ag}_{\mathrm{n}}\left(\mathrm{n}=5\right.$ and 15) clusters. The $\triangle E_{\text {HOMO-LUMO }}$ of the convex and concave forms (I) and (II) for $\mathrm{Ag}_{\mathrm{n}}(\mathrm{n}=5$ and 15) cluster are: [2.55 \& 2.66] and [3.85 \& 4.63] eV, respectively. The HOMO-LUMO gaps differences of convex and concave forms of GO-Ag $\left(\mathrm{n}=5\right.$ and 15) are: 0.11 and $0.78 \mathrm{eV}$. This gape differences for $\mathrm{GO}-\mathrm{Ag}_{15}$ is seven times more than $\mathrm{GO}-\mathrm{Ag}_{5}$. 

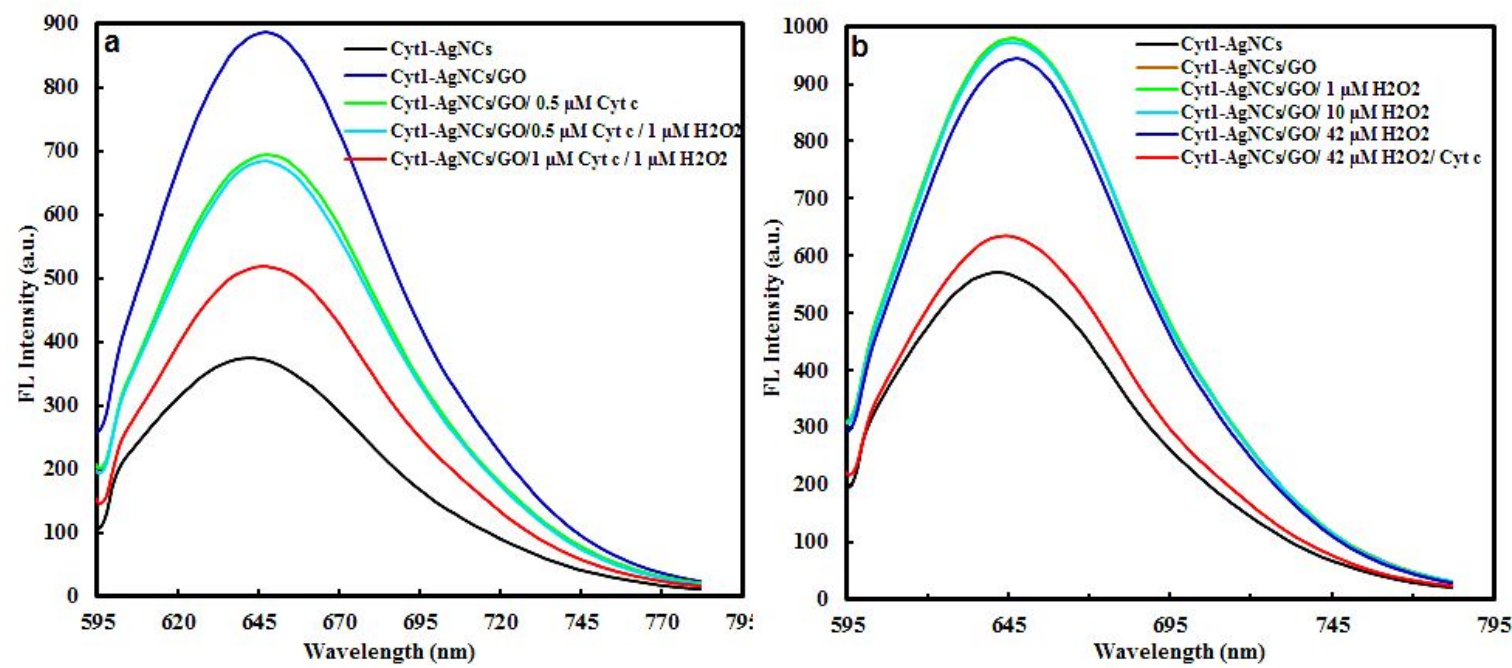

Figure S19. Fluorescence spectra of the Cyt1-AgNCs in the presence of GO, Cyt c and $\mathrm{H}_{2} \mathrm{O}_{2}$.

Table S2. Determination of Cyt $c$ in mES Cells and Spiked Samples $(n=3)$ treated with doxorubicin in different times after apoptosis induction.

\begin{tabular}{cccc} 
Time of doxorubicin treatment $(\mathrm{h})$ & Spiked $(\mathrm{nM})$ & Found $(\mathrm{nM}) \pm \mathrm{SD}$ & Recovery \\
& & & \\
Control & 0.00 & $9.44 \pm 0.56$ & - \\
& 24.16 & $36.17 \pm 2.93$ & 110.61 \\
& 46.15 & $55.13 \pm 4.74$ & 94.38 \\
& 66.17 & $76.59 \pm 5.60$ & 101.46 \\
2 & 0.00 & $12.54 \pm 0.75$ & - \\
& 24.16 & $33.45 \pm 2.27$ & 86.54 \\
& 46.15 & $56.21 \pm 4.44$ & 94.62 \\
6 & 66.17 & $72.35 \pm 7.38$ & 90.38 \\
& 0.00 & $31.34 \pm 2.23$ & - \\
& 24.16 & $52.56 \pm 3.90$ & 87.71 \\
& 46.15 & $76.92 \pm 7.46$ & 98.75 \\
& 66.17 & $98.72 \pm 8.00$ & 101.81 \\
& 0.00 & $18.16 \pm 0.98$ & - \\
& 24.16 & $41.23 \pm 3.54$ & 95.51 \\
& 46.15 & $62.38 \pm 5.93$ & 91.06 \\
& 66.17 & $87.15 \pm 7.93$ & 104.26 \\
& 0.00 & $13.61 \pm 1.02$ & - \\
& 24.16 & $35.21 \pm 2.74$ & 89.40 \\
& 46.15 & $61.30 \pm 5.40$ & 103.33 \\
& 66.17 & $81.11 \pm 6.41$ & 102.00 \\
\hline
\end{tabular}




\section{References}

1. Magde, D., Brannon, J. H., Cremers, T. L., Olmsted Iii, J. Absolute luminescence yield of cresyl violet. A standard for the red. Journal of Physical Chemistry 1979, 83 (6), 696-699.

2. Kovtyukhova, Nina I., Patricia J. Ollivier, Benjamin R. Martin, Thomas E. Mallouk, Sergey A. Chizhik, Eugenia V. Buzaneva, and Alexandr D. Gorchinskiy. Layer-by-layer assembly of ultrathin composite films from micron-sized graphite oxide sheets and polycations. Chemistry of Materials 1999, 11 (3), 771-778.

3. Nazari, M., Hosseinkhani, S. Design of disulfide bridge as an alternative mechanism for color shift in firefly luciferase and development of secreted luciferase. Photochemical \& Photobiological Sciences, 10 (7), 2011,1203-1215.

4. Debnath, S., Said, S. M., Roslan, M. F., Faizul, M., Sabri, M., Long, B. D. A DFT study on an alkali atom doped decahedral silver nanocluster for potential application in optoelectronics and catalysis. RSC Advances., 10 (5), 2015, 7665-7672.

5. Wen, X.; Yu, P.; Toh, Y.-R.; Lee, Y.-C.; Huang, K.-Y.; Huang, S.; Shrestha, S.; Conibeer, G.; Tang, J. Ultrafast electron transfer in the nanocomposite of the graphene oxide-Au nanocluster with graphene oxide as a donor. Journal of Materials Chemistry C 2014, 2 (19), $3826-3834$. 